\title{
Wykorzystanie techniki dynamicznego rozpraszania światła laserowego (DLS) do wyznaczania krytycznego stężenia micelizacji dodatków detergentowych w paliwie wysokoetanolowym
}

\begin{abstract}
Krytyczne stężenie micelizacji jest wartością charakteryzującą substancje posiadające właściwości powierzchniowo czynne, które przy odpowiednim stężeniu w roztworze tworzą micele. W artykule autorzy zaprezentowali wykorzystanie jednej z metod pomiaru krytycznego stężenia micelizacji - techniki dynamicznego rozpraszania światła laserowego - do wyznaczenia CMC pakietów dodatków detergentowych w benzynie z wysoką zawartością etanolu.

Słowa kluczowe: dynamiczne rozpraszanie światła laserowego, CMC, dodatek detergentowy, benzyna wysokoetanolowa.
\end{abstract}

\section{Use of dynamic light scattering (DLS) for the determination of critical micelle concentration of detergent additives in high ethanol-gasoline}

Critical micelle concentration is a value characterizing substances showing surface-active properties, which at the appropriate concentration in the solution form micelles. The authors of this paper, presented the application of one of the methods for critical micelle concentration measurement - the Dynamic Light Scattering (DLS) method - to determine the detergent additive packages CMC in gasoline with high content of ethanol.

Key words: dynamic light scattering, CMC, detergent additive, high ethanol-gasoline.

\section{Wprowadzenie}

Dodatki detergentowo-dyspergujące są jednymi z najczęściej stosowanych substancji przeznaczonych do uszlachetniania paliw w celu poprawy ich właściwości eksploatacyjnych $[3,7,14,15]$. W przypadku benzyn silnikowych tego typu dodatki mogą stanowić jedyną substancję wprowadzoną do paliwa na etapie blendingu [5, 9]. Cząsteczki dodatków detergentowych do paliw zbudowane są z długich łańcuchów węglowodorowych połączonych z polarnymi grupami funkcyjnymi. Specyficzne właściwości powierzchniowe detergentów są skutkiem ich amfifilowej struktury, utworzonej przez hydrofilowe i hydrofobowe fragmenty cząsteczek. Głównym zadaniem dodatków detergentowo-dyspergujących jest zapobieganie tworzeniu się osadów na elementach silnika, takich jak: układy wtrysku, zawory dolotowe, zawory wylotowe, komory spalania. Mechanizm działania dodatków detergentowo-dyspergujących jest bardzo złożony, jedna $\mathrm{z}$ teorii głosi, że związki powierzchniowo czynne obecne w paliwie przywierają do metalowych powierzchni silnika, zapobiegając w ten sposób przywieraniu osadów, natomiast według innej ich rola polega na dyspergowaniu osadów i zanieczyszczeń [13].

W ostatnich latach obserwowany jest wzrost udziału etanolu w benzynach silnikowych. Wynika on z dążenia do zwiększenia w ogólnym bilansie paliw udziału surowców odnawialnych. W wielu krajach, w tym w Polsce, stosuje się paliwa o niskiej zawartości etanolu (do kilku procent), jednak coraz częściej można zaobserwować zainteresowanie benzyną o wyższej zawartości etanolu (od 20\% (V/V) do $85 \%(V / V)$ ), 
przeznaczoną do zasilania specjalnych silników z zapłonem iskrowym $[1,8,10]$. Silniki takiej konstrukcji są już produkowane i od kilku lat obecne na rynku, np. silnik PSA BioFlex, GM FlexiFuel czy Fiat E.torQ.

Ze względu na odmienne właściwości fizykochemiczne i użytkowe benzyn wysokoetanolowych konieczne jest stosowanie innego typu dodatków detergentowo-dyspergujących oraz innych poziomów ich dozowania. Odpowiedni dobór stężenia i struktury chemicznej dodatku detergentowo-dyspergującego wymaga wykonania wielu kosztownych i czasochłonnych testów silnikowych, dlatego naukowcy podejmują próby wykorzystania innych pośrednich metod oceny skuteczności działania dodatków detergentowo-dyspergujących. Jedną $\mathrm{z}$ takich metod doboru optymalnego stężenia dodatku w paliwie może być wyznaczenie krytycznego stężenia micelizacji (CMC - critical micelle concentration) dodatku detergentowo-dyspergującego w paliwie. Przy niskich stężeniach cząsteczki detergentów w roztworze są niezasocjowane, jednak ze wzrostem ich stężenia na skutek oddziaływań międzycząsteczkowych dochodzi do ich agregacji, a w efekcie do tworzenia się miceli. Wartość stężenia detergentu w roztworze, przy której rozpoczyna się proces formowania miceli, nazywana jest krytycznym stężeniem micelizacji CMC. Na rysunku 1 przedstawiono najczęściej występujące rodzaje miceli [2].

CMC stanowi graniczną, maksymalną wartość stężenia dodatku, której przekroczenie nie poprawia właściwości detergentowo-dyspergujących uszlachetnianego paliwa.

Do wyznaczania CMC stosuje się różne metody, między innymi metody konduktometryczne, magnetyczny re-
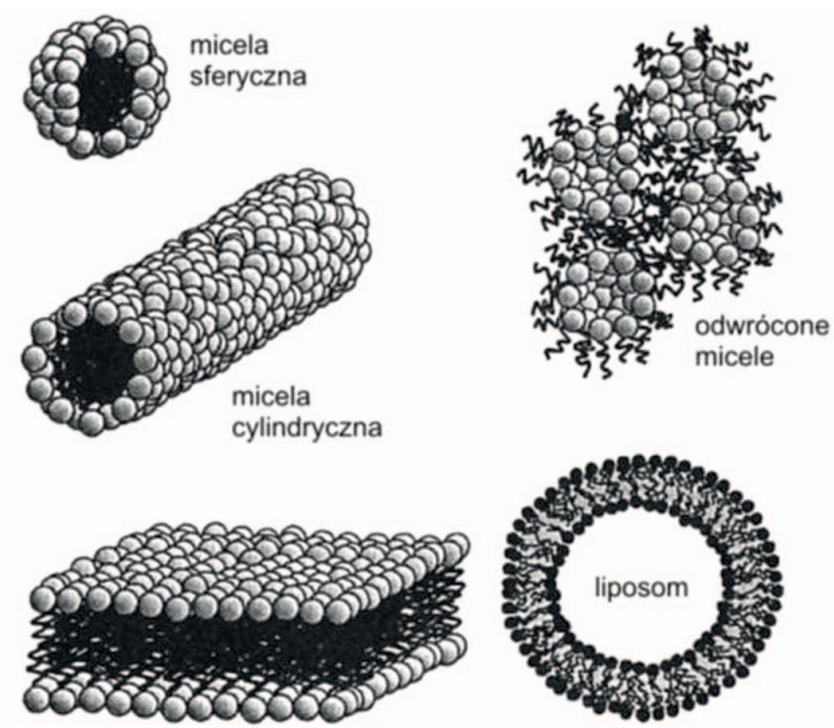

lamella (dwuwarstwa)

Rys. 1. Rodzaje miceli [2]

zonans jądrowy, rozpraszanie światła czy też pomiar napięcia powierzchniowego. W zależności od użytej metody wyznaczane wartości CMC dla danego surfaktantu mogą przyjmować nieznacznie różne wartości [4].

Analiza zjawiska asocjacji cząsteczek substancji powierzchniowo czynnych w znacznie większe układy micelarne pozwala wykorzystać również do wyznaczania krytycznego stężenia micelizacji zjawisko dynamicznego rozpraszania promieniowania laserowego, które umożliwia precyzyjne określenie rozmiarów cząstek w dyspersjach cieczowych $[6,11,12]$.

\section{Aparatura pomiarowa}

Analizator Zetasizer Nano S pozwalał na wyznaczenie średnicy cząstek w zakresie od $0,6 \mathrm{~nm}$ do $6000 \mathrm{~nm}$ oraz masy cząsteczkowej w zakresie od $1 \times 10^{3} \mathrm{Da}$ do $2 \times 10^{7} \mathrm{Da}$ w dyspersjach cieczowych. Wielkości nanocząstek określano na podstawie analizy szybkości ruchów Browna molekuł w próbce metodą spektroskopii korelacyjnej fotonów.

W aparacie Zetasizer Nano S jako źródło promieniowania zastosowano monochromatyczny spójny laser helowo-neonowy (He-Ne) o długości fali 632,8 nm. W celu zogniskowania promieni w objętości pomiarowej układ optyczny wyposażono w zespół soczewek. Energia promieniowania lase- ra po przejściu przez próbkę była silnie osłabiana przez wygaszacz wiązki pierwotnej. Promieniowanie rozproszone pod kątem $\theta$ docierało do detektora o odpowiedniej optyce.

Aparat mierzył natężenie światła rozproszonego pod kątem $173^{\circ}$ (rozpraszanie wsteczne). W analizatorze zastosowano nowatorską technikę NIBS (non-invasive back scatter), która minimalizowała tak zwane rozpraszanie wtórne. Sygnał $\mathrm{z}$ detektora po wzmocnieniu podawany był $\mathrm{w}$ formie cyfrowej do korelatora. Towarzyszący aparatowi komputer wykorzystywano do sterowania pomiarem, przechowywania danych i obliczania wyników.

\section{Materiały}

Do badań wykorzystano benzynę silnikową o właściwościach zamieszczonych w tabeli 1 . Benzyna zawierała $85 \%(V / V)$ etanolu i $15 \%(V / V)$ benzyny węglowodorowej. Paliwo skomponowane w INiG - PIB odpowiada skła- dem i właściwościami handlowej wysokoetanolowej benzynie sprzedawanej w wielu krajach, m.in. w Szwecji i Norwegii. Benzyna służy do zasilania silników z zapłonem iskrowym typu flex-fuel. 
Tablica 1. Właściwości fizykochemiczne paliwa bazowego stosowanego do badań

\begin{tabular}{|c|c|c|c|}
\hline Wymagania & $\begin{array}{l}\text { Wynik } \\
\text { badania }\end{array}$ & $\begin{array}{l}\text { Wymagania według } \\
\text { PKN-CEN/TS } 15293\end{array}$ & $\begin{array}{l}\text { Metoda badania } \\
\text { według }\end{array}$ \\
\hline Gęstość (w temperaturze $15^{\circ} \mathrm{C}$ ) $\left[\mathrm{kg} / \mathrm{m}^{3}\right]$ & 784 & $760,0 \div 800,0$ & EN ISO 12185 \\
\hline Okres indukcyjny [min] & $>360$ & $\min .360$ & EN ISO 7536 \\
\hline Zawartość żywic obecnych [mg/100 ml] & $<1$ & maks. 5 & EN ISO 6246 \\
\hline Działanie korodujące na płytce miedzianej ( $3 \mathrm{~h} \mathrm{w}$ temperaturze $\left.50^{\circ} \mathrm{C}\right)$ [klasa] & $1 \mathrm{~A}$ & 1 & EN ISO 2160 \\
\hline Całkowita kwasowość (w przeliczeniu na kwas octowy) $[\%(\mathrm{~m} / \mathrm{m})]$ & $<0,003$ & maks. 0,005 & EN ISO 15491 \\
\hline Przewodność elektryczna $[\mu \mathrm{S} / \mathrm{cm}]$ & 1,0 & maks. 1,5 & EN 15938 \\
\hline Zawartość metanolu $[\%(V / V)]$ & $<0,17$ & maks. 1,0 & EN 1601 \\
\hline $\begin{array}{l}\text { Zawartość wyższych nasyconych alkoholi jednowodorotlenowych }\left(\mathrm{C}_{3}-\mathrm{C}_{5}\right) \\
{[\%(V / V)]}\end{array}$ & 2,5 & maks. 6,0 & EN 1601 \\
\hline Zawartość eterów (z pięcioma lub więcej atomami węgla) [\% $(V / V)]$ & $<0,17$ & maks. 11,0 & EN 1601 \\
\hline Zawartość wody $[\%(\mathrm{~m} / \mathrm{m})]$ & 0,118 & maks. 0,400 & EN 15489 \\
\hline Zawartość chlorków nieorganicznych [mg/kg] & $<1,0$ & maks. 1,2 & EN 15492 \\
\hline Zawartość miedzi [mg/kg] & $<0,05$ & maks. 0,10 & EN 15837 \\
\hline Zawartość fosforu [mg/l] & $<0,15$ & maks. 0,15 & EN 15487 \\
\hline Zawartość siarki [mg/kg] & $<5,0$ & maks. 10,0 & EN 15486 \\
\hline Zawartość siarczanów [mg/kg] & 2,7 & maks. 4,0 & EN 15492 \\
\hline Prężność par [kPa] & 45,2 & $\begin{array}{c}35,0 \div 60,0 \\
\text { klasa A }\end{array}$ & EN 13016-1 \\
\hline
\end{tabular}

Przygotowane do badań formulacje pakietów dodatków detergentowych zawierały otrzymane $\mathrm{w}$ INiG - PIB dodatki o właściwościach detergentowo-dyspergujących, handlowy olej nośny oraz rozpuszczalnik.

\section{Pakiet NOR 15:}

Pakiet dodatków zawierał dodatek o właściwościach detergentowo-dyspergujących o strukturze N-alkilowanej pochodnej benzoksazyny uwodornionej w pierścieniu heterocyklicznym, dodatkowo podstawionej resztą alkilową w pierścieniu aromatycznym, oraz syntetyczny olej nośny o strukturze oksyalkilowanego alkilofenolu i rozpuszczalnik aromatyczny.

\section{Pakiet NOR 20:}

Pakiet dodatków zawierał dodatek o właściwościach detergentowo-dyspergujących o strukturze diaminy, pochodnej alkilofenolu, zawierającej struktury II- i III-rzędowej aminy, oraz syntetyczny olej nośny o strukturze oksyalkilowanego alkilofenolu i rozpuszczalnik aromatyczny.

Próbki do badań przygotowywano poprzez zmieszanie odpowiednich pakietów NOR 15 i NOR 20 z benzyną E85 o właściwościach z tablicy 1 . Próbki mieszano za pomocą mieszadła mechanicznego z szybkością $500 \mathrm{obr} / \mathrm{min}$ przez 30 minut. Próbki analizowano po 30 minutach od zakończenia mieszania.

\section{Metodyka badań}

Pomiary przeprowadzono $\mathrm{w}$ temperaturze $25^{\circ} \mathrm{C}$, stosując kuwety pomiarowe wykonane ze szkła optycznego o drodze optycznej równej $1 \mathrm{~cm}$. Ze względu na to, że wszystkie badane roztwory były bardzo rozcieńczone (maksymalnie $0,1 \%(\mathrm{~m} / \mathrm{m})$, przyjęto założenie, że ich lepkość była równa lepkości paliwa etanolowego E85. Ustalono parametry pracy analizatora i podano je w tablicy 2 .

Podstawą do wyznaczenia krytycznego stężenia micelizacji z wykorzystaniem metody dynamicznego rozpraszania promieniowania laserowego były zależności wskaźnika zli- czeń i hydrodynamicznej średnicy cząstek od stężenia substancji w badanym roztworze. W roztworze, w którym nie tworzą się micele, aparat nie powinien rejestrować obecności cząstek, natomiast po przekroczeniu stężenia micelizacji obserwowano pik o mierzalnej średnicy hydrodynamicznej (dolna granica wykrywalności średnicy cząstek w aparacie Zetasizer Nano $\mathrm{S}$ to $0,6 \mathrm{~nm}$ ). W rzeczywistości jednak w roztworach o stężeniach mniejszych niż CMC rejestrowano pewne piki, ale ich kształt, intensywność, charakter i brak powtarzalności wskazywały na to, że były to szumy. 
Tablica 2. Parametry pracy analizatora

\begin{tabular}{|l|c|}
\hline \multicolumn{1}{|c|}{ Parametr } & Wartość \\
\hline Współczynnik absorpcji & 0,01 \\
\hline Czas stabilizowania temperatury $[\mathrm{min}]$ & 10 \\
\hline Czas pomiaru & automatyczny - dobierany według algorytmu oprogramowania analizatora \\
\hline Liczba pomiarów & 3 \\
\hline Odstępy między pomiarami [min] & 5 \\
\hline Pozycja pomiarowa & automatyczna - dobierana według algorytmu oprogramowania analizatora \\
\hline Tłumienie wiązki promieniowania & automatyczne - dobierane według algorytmu oprogramowania analizatora \\
\hline Model obliczenia wyniku & General purpose \\
\hline
\end{tabular}

Wartości wskaźnika zliczeń, czyli liczby zarejestrowanych fotonów na sekundę, zwiększały się w nieznacznym stopniu w miarę wzrostu stężenia, natomiast po przekroczeniu wartości krytycznego stężenia micelizacji obserwowano gwałtowny wzrost wartości tego parametru, będący efektem tworzenia się miceli.

W celu wyznaczenia krytycznego stężenia micelizacji pakietów dodatków NOR 15 i NOR 20 dla każdego z nich wykonano siedem roztworów o stężeniu $62,5 \mathrm{mg} / \mathrm{kg}, 125 \mathrm{mg} / \mathrm{kg}$, $250 \mathrm{mg} / \mathrm{kg}, 500 \mathrm{mg} / \mathrm{kg}, 600 \mathrm{mg} / \mathrm{kg}, 800 \mathrm{mg} / \mathrm{kg}$ i $1000 \mathrm{mg} / \mathrm{kg}$ pakietu dodatków detergentowych w benzynie E85. Dla każdej z badanych próbek wykonano po trzy pomiary rozkładów wielkości cząstek. W przypadku benzyny E85 niezawierającej pakietu dodatków oraz benzyn zawierających pakiety NOR 15 lub NOR 20 w stężeniu niższym niż 600 mg/kg analizator nie rejestrował spójnego rozkładu wielkości cząstek (obserwowano jedynie szumy). Krzywe rozkładu wielkości cząstek benzyn zawierających $600 \mathrm{mg} / \mathrm{kg}$ lub więcej pakietu dodatków NOR 15 przedstawiono na rysunku 2, natomiast pakietu NOR 20 - na rysunku 3.

Benzyna E85 zawierająca pakiet dodatków NOR 15 w stężeniach powyżej $600 \mathrm{mg} / \mathrm{kg}$ charakteryzowała się obecnością cząstek o rozmiarach 120 $\div 140 \mathrm{~nm}$ (dominujący pik). Dodatkowo zaobserwowano niewielką ilość cząstek o średnicach około $2 \div 5 \mathrm{~nm}$ w próbkach zawierających $800 \mathrm{mg} / \mathrm{kg}$ i $1000 \mathrm{mg} / \mathrm{kg}$ pakietu dodatków.

Benzyna E85 zawierająca pakiet dodatków NOR 20 w stężeniach powyżej $600 \mathrm{mg} / \mathrm{kg}$ charakteryzowała się obecnością cząstek o rozmiarach $200 \div 240 \mathrm{~nm}$ (dominujący pik). Dodatkowo zaobserwowano niewielką ilość cząstek o średnicach około $10 \div 30 \mathrm{~nm}$ dla próbek zawierających $600 \mathrm{mg} / \mathrm{kg}$ i $800 \mathrm{mg} / \mathrm{kg}$ pakietu dodatków.

Wartości średnich średnic hydrodynamicznych cząstek odczytano z otrzymanych krzywych rozkładów wielkości cząstek i sporządzono wykresy ich zależności od stężenia pakietu dodatków NOR 15 (kolor czerwony) i pakietu dodatków NOR 20 (kolor niebieski) - rysunek 4.
W przedziale stężeń $62,5 \div 500 \mathrm{mg} / \mathrm{kg}$ dla benzyn uszlachetnionych zarówno pakietem dodatków NOR 15, jak i NOR 20 nie zarejestrowano wyników pomiarów średnicy hydrodynamicznej o intensywności znacznie wyższej niż szum, co mogło świadczyć o braku miceli w roztworach o podanych powyżej wartościach stężeń. Po przekroczeniu wartości stęże-

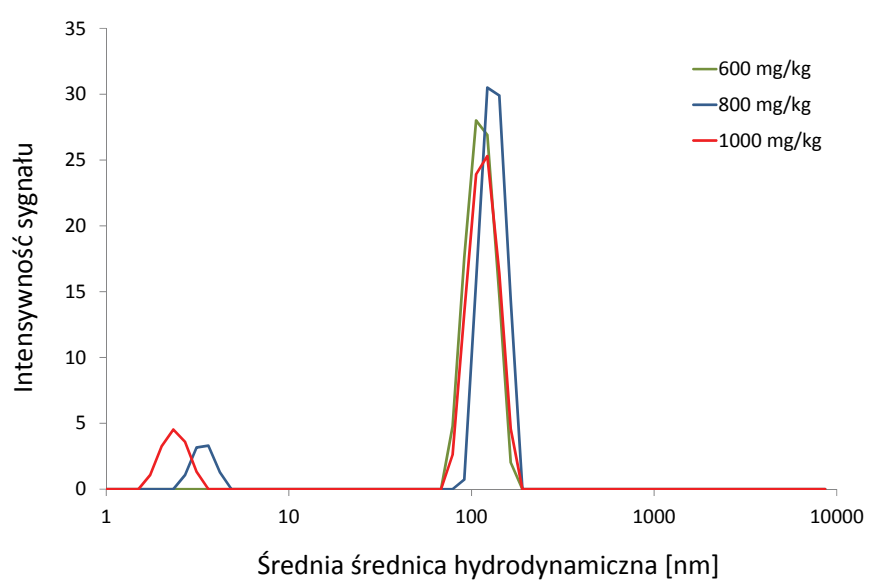

Rys. 2. Krzywe rozkładu wielkości cząstek (średnia z trzech pomiarów) benzyn E85 zawierających $600 \mathrm{mg} / \mathrm{kg}, 800 \mathrm{mg} / \mathrm{kg}$ lub $1000 \mathrm{mg} / \mathrm{kg}$ pakietu dodatków NOR 15

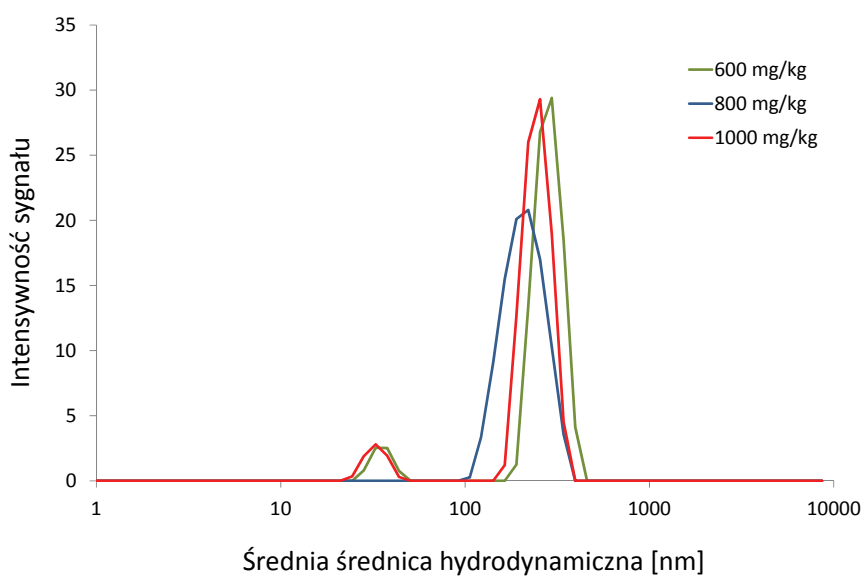

Rys. 3. Krzywe rozkładu wielkości cząstek (średnia z trzech pomiarów) benzyn E85 zawierających $600 \mathrm{mg} / \mathrm{kg}, 800 \mathrm{mg} / \mathrm{kg}$ lub $1000 \mathrm{mg} / \mathrm{kg}$ pakietu dodatków NOR 20 


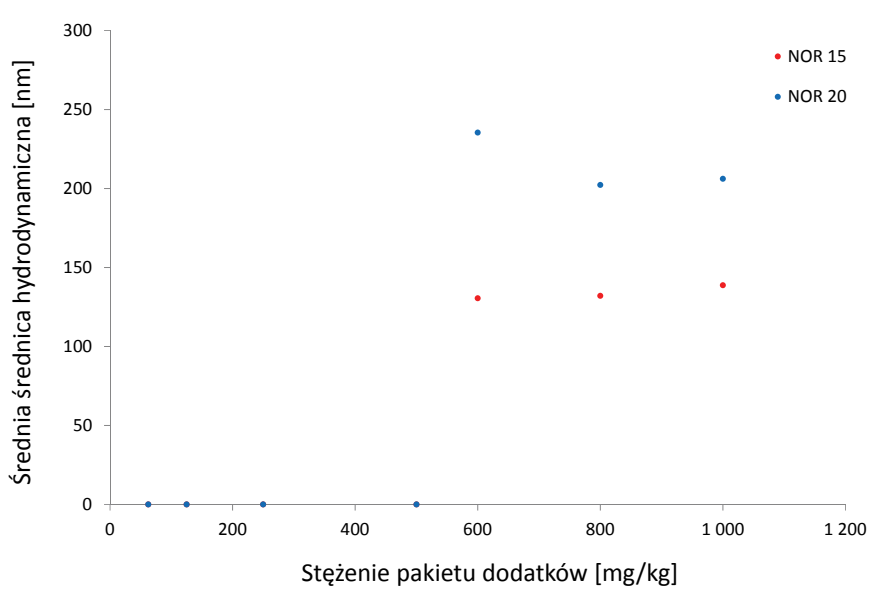

Rys. 4. Wykresy zależności średniej średnicy hydrodynamicznej cząstek (dominujący plik) od stężenia pakietów dodatków NOR 15 i NOR 20

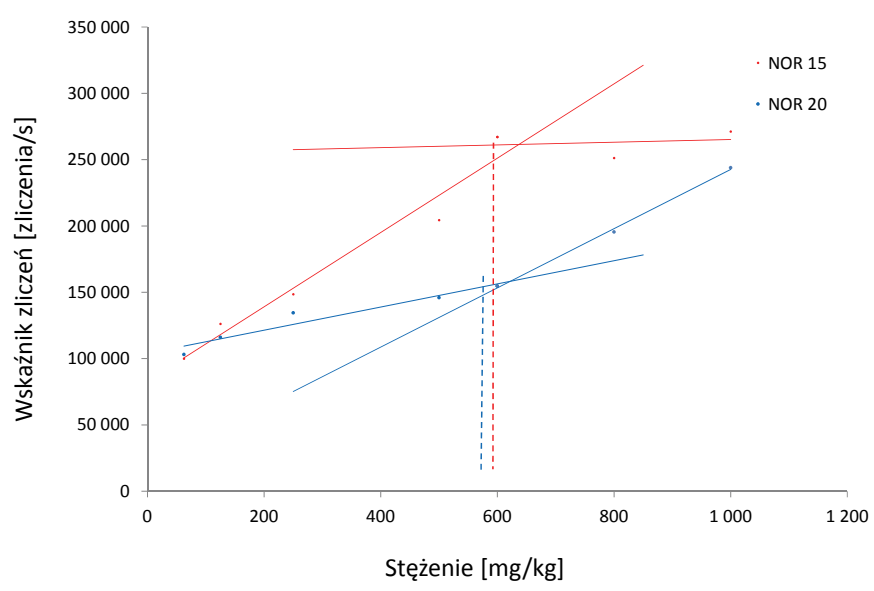

Rys. 5. Wykresy zależności średniego wskaźnika zliczeń od stężenia pakietu NOR 15 lub NOR 20

nia pakietu NOR 15 równego $600 \mathrm{mg} / \mathrm{kg}$ pojawiły się sygnały cząstek o rozmiarze hydrodynamicznym równym 130,6 nm. Wartość średnicy hydrodynamicznej wytworzonych miceli ze wzrostem stężenia pakietu NOR 15 zwiększała się nieznacznie, osiągając wartość $138,8 \mathrm{~nm}$ przy stężeniu $1000 \mathrm{mg} / \mathrm{kg}$.
W przypadku benzyn zawierających pakiet NOR 20 o stężeniu $600 \mathrm{mg} / \mathrm{kg}$ maksimum dominującego piku przypadało na wartość równą 235,4 nm. Wartość średnicy hydrodynamicznej wytworzonych miceli nie była stała wraz ze wzrostem stężenia pakietu dodatków NOR 20, lecz spadała do wartości $202,2 \mathrm{~nm}$ i $206,1 \mathrm{~nm}$ przy stężeniach odpowiednio $800 \mathrm{mg} / \mathrm{kg}$ i $1000 \mathrm{mg} / \mathrm{kg}$. Zjawisko to związane było prawdopodobnie ze zmniejszeniem objętości miceli pod wpływem oddziaływań między cząsteczkami.

Mimo że dla benzyn zawierających od $62,5 \mathrm{mg} / \mathrm{kg}$ do $500 \mathrm{mg} / \mathrm{kg}$ pakietu dodatków NOR 15 lub NOR 20 analizator nie rejestrował spójnego rozkładu wielkości cząstek, istniała możliwość odczytu wskaźnika zliczeń. Na rysunku 5 zilustrowano zależność zmierzonego wskaźnika zliczeń od stężenia pakietu dodatków detergentowych NOR 15 lub NOR 20 w benzynach E85.

W przypadku benzyn zawierających pakiet dodatków NOR 15 (czerwona linia na rysunku 5) wskaźnik zliczeń wynosił około $100000 \div 270000$ cps. W zakresie stężeń $62,5 \div 600 \mathrm{mg} / \mathrm{kg}$ parametr ten wzrastał liniowo do wartości około 270000 cps. Roztwory zawierające $600 \div 1000 \mathrm{mg} / \mathrm{kg}$ pakietu charakteryzowała natomiast niemal identyczna wartość wskaźników zliczeń, wynosząca około $270000 \mathrm{cps}$.

W benzynach z pakietem dodatków NOR $20 \mathrm{w}$ ilości $62,5 \div 600 \mathrm{mg} / \mathrm{kg}$ obserwowano stopniowe niewielkie wzrosty wskaźników zliczeń (w zakresie około $100000 \div 150000 \mathrm{cps}$ ). Roztwory o stężeniach wyższych niż $600 \mathrm{mg} / \mathrm{kg}$ charakteryzował natomiast dynamiczny wzrost wskaźnika zliczeń, aż do osiągnięcia wartości prawie $250000 \mathrm{cps}$ przy stężeniu równym $1000 \mathrm{mg} / \mathrm{kg}$.

Na podstawie wyników pomiarów wskaźników zliczeń oraz wartości rozmiarów średnich średnic hydrodynamicznych miceli w roztworach zarówno dla pakietu NOR 15 , jak i NOR 20 stwierdzono, że krytyczne stężenie micelizacji dla tej substancji mieściło się w zakresie 500 $600 \mathrm{mg} / \mathrm{kg}$.

\section{Podsumowanie}

Wykorzystano metodę dynamicznego rozpraszania światha do wyznaczenia krytycznego stężenia micelizacji. Zbadano CMC dwóch pakietów dodatków: NOR 15 i NOR 20 $(500 \div 600 \mathrm{mg} / \mathrm{kg})$ w benzynie E85. Wartości wyznaczonych stężeń pokrywają się z wielkościami optymalnego dozowania pakietów w benzynie E85, wyznaczonymi podczas ba- dań przeprowadzonych w hamowni silnikowej. Na podstawie uzyskanych wyników badań wykazano przydatność tej metody do szacowania tego parametru dla związków powierzchniowo czynnych. Metoda ta może służyć jako narzędzie do szybkiego szacowania optymalnego dozowania substancji powierzchniowo czynnych w paliwach.

Prosimy cytować jako: Nafta-Gaz 2016, nr 12, s. 1144-1149, DOI: 10.18668/NG.2016.12.19

Artykuł nadesłano do Redakcji 26.08.2016 r. Zatwierdzono do druku 10.12.2016 r.

Artykuł powstał na podstawie pracy badawczej finansowanej ze środków funduszy norweskich w ramach programu Polsko-Norweska Współpraca Badawcza pt. Influence of bioethanol fuels treatment for operational performance, ecological properties and GHG emissions of spark ignitron engine. 


\section{Literatura}

[1] Aleiferis P.G., Serras-Pereira J., van Romunde Z., Caine J., Wirth M.: Mechanisms of spray formation and combustion from a multi-hole injector with E85 and gasoline. Comb. and Flame 2010, vol. 157, no. 4, s. 735-756.

[2] Butt H.J., Graf K., Kappl M.: Physics and chemistry of interfaces. Wiley-VCH, Berlin 2003.

[3] Ferreira da Silva M.P., Rodrigues e Brito L., Honorato F.A., Silveira Paim A.P., Pasquini C., Primentel M.F.: Classification of gasoline as with or without dispersant and detergent additives using infrared spectroscopy and multivariate classification. Fuel 2014, vol. 116, s. 151-157.

[4] Hiemenz P.C., Rajagopalan R.: Principles of colloid and surface chemistry. Taylor \& Francis, New York 1997.

[5] Manzetti S., Andersen O.: A review of emission products from bioethanol and its blends with gasoline. Background for new guidelines for emission control. Fuel 2015, vol. 140, s. 293-301.

[6] Menta M., Frayret J., Grassl B., Gleyzes Ch., Castetbon A., Potin-Gautier M.: Development of an alternative analytical methodology to monitor industrial degreasing baths by dynamic light scattering. J. Cleaner Prod. 2016, vol. 113, s. 981-988.

[7] Nassar A.M., Ahmed N.S., Abdel-Hameed H.S., El-Kafrawy A.F.: Synthesis and utilization of non-metallic detergent/ dispersant and antioxidant additives for lubricating engine oil. Trib. Int. 2016, vol. 93, s. 297-305.

[8] Pałuchowska M., Danek B.: Specyfikacje jakościowe bioetanolu i biopaliw do silników o zapłonie iskrowym. Nafta-Gaz 2009, nr 2, s. 174-182.

[9] Pinto V.S., Gambarra-Neto F.F., Flores I.S., Monteiro M.R., Liao L.M.: Use of $1 H$ NMR and chemometrics to detect additives present in the Brazilian commercial gasoline. Fuel 2016, vol. 182, s. 27-33.

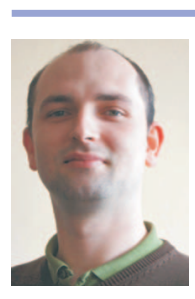

Mgr Michał WOJTASIK

Asystent w Zakładzie Dodatków i Nowych

Technologii Chemicznych.

Instytut Nafty i Gazu - Państwowy Instytut Badawczy

ul. Lubicz 25 A

31-503 Kraków

E-mail:michal.wojtasik@inig.pl
[10] Sarjovaara T., Larmi M.: Dual fuel diesel combustion with an E85 ethanol/gasoline blend. Fuel 2015, vol. 139, s. 704-714.

[11] Surfactant micelle characterization using dynamic light scattering. Malvern Application Note nr MRK809-0.

[12] Topel O., Cakar B.A., Budama L., Hoda N.: Determination of critical micelle concentration of polybutadiene-block-poly(ethyleneoxide) diblock copolymer by fluorescence spectroscopy and dynamic light scattering. J. Mol. Liqu. 2013, vol. 177 , s. 40-43.

[13] Uy D., Ford M.A., Jayne D.T., Neil A.E.O., Haack L.P., Hangas J., Jagner M.J., Sammut A., Gangopadhay A.K.: Characterization of gasoline soot and comparison to diesel soot: Morphology, chemistry and wear. Trib. Int. 2014, vol. 80, s. $198-209$.

[14] Żak G., Ziemiański L., Stępień Z., Wojtasik M.: Engine testing of novel diesel fuel detergent-dispersant additives. Fuel 2014, vol. 122, s. 12-20.

[15] Żak G., Ziemiański L., Stępień Z., Wojtasik M.: Problemy zwiazane z tworzeniem się osadów na elementach uktadów wtryskowych nowoczesnych silników Diesla - przyczyny, metody badań, przeciwdziałanie. Nafta Gaz 2013, nr 9, s. $702-708$.

Dr Grażyna ŻAK
Adiunkt w Zakładzie Dodatków i Nowych
Technologii Chemicznych.
Instytut Nafty i Gazu - Państwowy Instytut Badawczy
ul. Lubicz 25 A
31-503 Kraków
E-mail: grazyna.zak@inig.pl

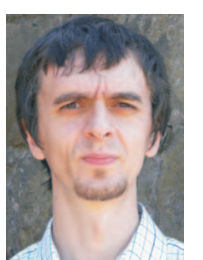

Mgr inż. Jarosław MARKOWSKI

Asystent w Zakładzie Dodatków i Nowych

Technologii Chemicznych.

Instytut Nafty i Gazu - Państwowy Instytut Badawczy ul. Lubicz 25 A

31-503 Kraków

E-mail: jaroslaw.markowski@inig.pl 